\title{
Research on Human Capital Model Based on Layered Complex Network
}

\author{
Yang Zhang a , Lei Huang ${ }^{b}$ \\ ${ }^{1}$ School of Economics and Management, Beijing Jiaotong University, Beijing 100044, China; \\ aswuzhangyang@163.com, ${ }^{b}$ lhuang@ bjtu.edu.cn
}

Keywords: Multilayer and Complex Network, Human Capital, AHP.

\begin{abstract}
To draw a network of a company which has 370 employees, the paper constructs a human resources network based on layered complex networks. In this network, nodes represent employees, so it has 370 nodes and nodes are given weights, which derived from the employee level, human capital and employee personal accomplishment using AHP comprehensive assessment. The connection between the nodes represents the direct partnership between employees, thus constituting the initial complex network. Because human capital has the level attributes, the complex network is divided into high-level cadres, middle-level cadres and low-level employees three levels, using clustering coefficient, network density, and hierarchical recursive algorithm to analyze the characteristic of the network. This paper makes a detailed understanding of the human capital and management and raise a human capital model based on complex hierarchical network. More comprehensive consideration of the effect of changes in human capital can provide a good reference for HR.
\end{abstract}

\section{Introduction}

Human resource (HR) specialists help senior leadership manage personnel by improving retention and motivation, coordinating training, and building good teams. Managing the fluid network of human capital within an organization requires understanding personnel loyalties to the company and to subgroups; building trust in the workplace; and managing the formation, dissolution and retention of formal and informal ties between people. When people leaving for other jobs or retiring are replaced, the resulting turbulence is collectively termed organizational "churn". As a result of that, we build a series of models to study Human Capital and churn.

This paper takes an organization of 370 people called A as an example which is in a highly competitive market place, leading to challenging issues related to effectively managing its human capital. The company now faces a series of problems. The company has never conducted any analyses, modeling or simulation of the HR functions of the company. It is time to build a network model to map human resources in the organization.

The HR manager has recently put together a comprehensive organizational graph (Fig. 1) and detailed statistics describing the basic structure, staffing, recruiting costs, training costs, and salaries of the company employees (Table 1). Fig. 1: Each branch or staff office with an * consists of two divisions of 7 people. Otherwise, each entry in this chart without an * consists of 4 staff people. Table 1: The median income of the company is defined as $\sigma$. The value of $\sigma$ does rise slowly with the inflation rate so all the decision makers are comfortable with reports and decisions based on the changing and relative value of $\sigma$, instead of exact monetary values.

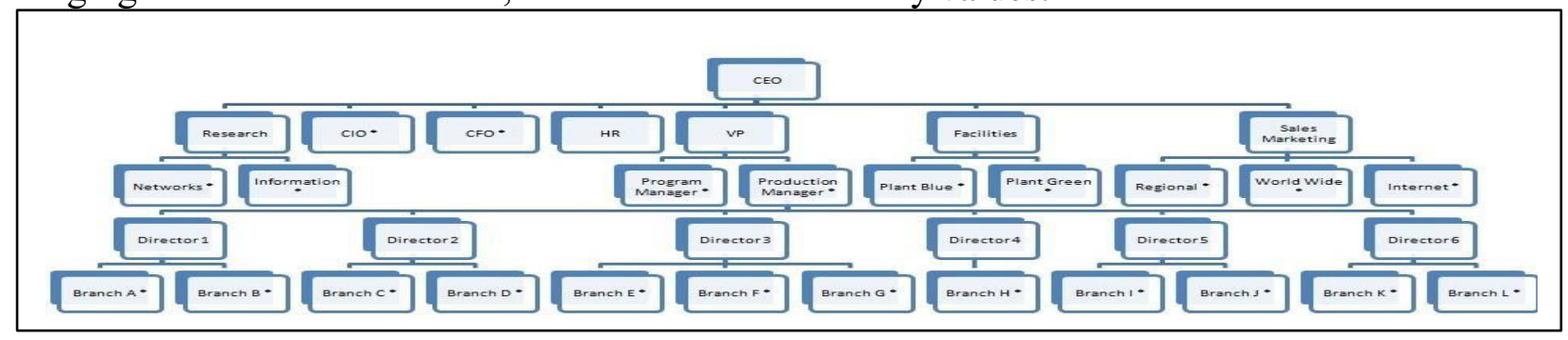

Fig. 1 Comprehensive organizational graph 
Table 1 Important HR data

\begin{tabular}{|c|c|c|c|c|c|}
\hline Level of Position & $\begin{array}{c}\text { Median time to } \\
\text { recruit } \\
\text { (months) }\end{array}$ & $\begin{array}{c}\text { Median cost of } \\
\text { recruitment (\$) }\end{array}$ & $\begin{array}{c}\text { Number of } \\
\text { Employees at this } \\
\text { level }\end{array}$ & $\begin{array}{c}\text { Average annual } \\
\text { salary rate for } \\
\text { this level (\$) }\end{array}$ & $\begin{array}{c}\text { Average } \\
\text { annual training } \\
\text { cost (\$) }\end{array}$ \\
\hline Senior manager/Executive & 7 & $1.2 \sigma$ & 10 & $8 \sigma$ & $0.5 \sigma$ \\
\hline Junior manager/Executive & 6 & $0.7 \sigma$ & 20 & $4 \sigma$ & $0.6 \sigma$ \\
\hline $\begin{array}{c}\text { Experienced supervisor } \\
\text { (Branch) }\end{array}$ & 5 & $0.6 \sigma$ & 25 & $2 \sigma$ & $0.2 \sigma$ \\
\hline $\begin{array}{c}\text { Inexperienced supervisor } \\
\text { (Division) }\end{array}$ & 4 & $0.6 \sigma$ & 25 & $1.5 \sigma$ & $0.3 \sigma$ \\
\hline $\begin{array}{c}\text { Experienced employee } \\
\text { Inexperienced employee }\end{array}$ & 1 & $0.3 \sigma$ & 110 & $\sigma$ & $0.1 \sigma$ \\
\hline Administrative clerk & 2 & $0.1 \sigma$ & 150 & $0.9 \sigma$ & $0.3 \sigma$ \\
\hline
\end{tabular}

\section{Build the Complex Network Model}

In this article, the node is described as employees, and the connection between the nodes is represented as a partnership. The node has weights. Node weights is decided by several factors. And then assess the value of the employees in the company.

\subsection{Influencing Factors of Node Weight}

It is supposed that the value of employee evaluation is described by the following aspects: the employee's level, human capital of employee and personal accomplishment.

1. The description of employee's level

Suppose that employee's grade is described by number 1 to 6. Senior manager/Executive: 1, Junior manager/Executive: 5, Experienced supervisor (Branch): 4, Inexperienced supervisor (Division): 3, Experienced employee: 2, inexperienced employee and Administrative clerk: 1.

\section{Human capital of employees}

If use quantization to represent the human capital, we will calculation the human capital by "historical cost" calculation. The thinking of the historical cost method is: human capital value is equal to the sum of all costs and expenses for human capital. So we boldly assume that each employee's human capital described as follows:

Human Capital=Median cost of recruitment + Average annual salary rate for this level + Average annual training cost.

So each level of employee human capital as follows: Senior manager/Executive: 9.7б, Junior

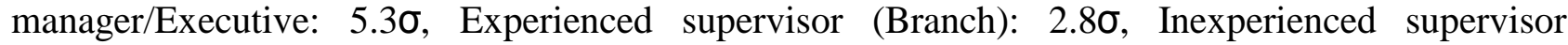

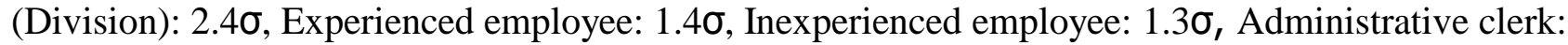
$1.25 \sigma$.

\section{Personal accomplishment}

According to the problem of employees' churn in the title, employees will be measured; personal accomplishment following aspects: loyalty, responsibility (when facing colleagues' quit) and professional ability. It could be assumed that all levels of staff quality ratings (Table 2). 
Table 2 Staff quality ratings (Full score is 1).

\begin{tabular}{|c|c|c|c|c|}
\hline Level of Position & Loyalty & Responsibility & $\begin{array}{c}\text { Professional } \\
\text { competence }\end{array}$ & Complex \\
\hline Senior manager/Executive & 0.8 & 0.8 & 0.7 & 0.77 \\
\hline Junior manager/Executive & 0.6 & 0.5 & 0.4 & 0.5 \\
\hline Experienced supervisor(Branch) & 0.4 & 0.5 & 0.7 & 0.67 \\
\hline $\begin{array}{c}\text { Inexperienced } \\
\text { supervisor(Division) }\end{array}$ & 0.6 & 0.4 & 0.4 & 0.47 \\
\hline Experienced employee & 0.4 & 0.5 & 0.6 & 0.5 \\
\hline Inexperienced employee & 0.6 & 0.4 & 0.4 & 0.47 \\
\hline Administrative clerk & 0.5 & 0.5 & 0.5 & 0.5 \\
\hline
\end{tabular}

\subsection{Calculate Node Weight.}

Use AHP to determine the weight of each index, and finally calculate the weight of each node based on the weight of each index.

Objectively, each similar system's similar elements consist of similar features which have affects are not equivalent. We put similar elements as an evaluation factor and build an evaluation factor set.

$$
U=\left\{u_{1}, u_{2}, \cdots, u_{i}, \cdots, u_{N}\right\}
$$

In the above expression $u_{i} \in U,(i=1,2, \ldots N)$. Assume that $u_{i j}$ is expressed as importance of setting values for $u_{i}$ to $u_{j}$ where $j=1,2, \ldots N$. The value of $u_{i j}$ use common method of 1 to 9 scale. (Table 3 )

Table 3 Judge matrix's scale definition [1]

\begin{tabular}{|c|c|}
\hline Scaling $\left(\right.$ Value of $\left.u_{i j}\right)$ & Definition(Level of importance) \\
\hline 1 & $u_{i}$ as important to $u_{j}$ \\
\hline 3 & $u_{i}$ slightly more important than $u_{j}$ \\
\hline 5 & $u_{i}$ obviously more important than $u_{j}$ \\
\hline 7 & $u_{i}$ strongly more important than $u_{j}$ \\
\hline 9 & $u_{i}$ strongly more important than $u_{j}$ \\
\hline $2,4,6,8$ & When two-degree mark are between adjacent judgment, take the median \\
\hline
\end{tabular}

According to the definition of the scale and compare the factors set $U$, we structure the judgment matrix $\mathrm{P}$ as follows.

$$
P=\left\{\begin{array}{cccccc}
u_{11} & u_{12} & \cdots & u_{1 j} & \cdots & u_{1 N} \\
u_{21} & u_{21} & \cdots & u_{2 j} & \cdots & u_{2 N} \\
\cdots & \cdots & & \cdots & \cdots & \\
u_{i 1} & u_{i 2} & \cdots & u_{i j} & \cdots & u_{i N} \\
\cdots & \cdots & & \cdots & & \cdots \\
u_{N 1} & u_{N 2} & \cdots & u_{N j} & \cdots & u_{N N}
\end{array}\right\}
$$

In the matrix $\mathrm{P}, u_{i j}>0, u_{i j}=1 / u_{j i}(i=1,2, \cdots, N)$. In addition, to the judgment matrix $\mathrm{P}$, if for any $\mathrm{i}$, $\mathrm{j}, \mathrm{k}$ there are $u_{i j}=1$, call the matrix consistency matrix.

The problem of using AHP to determine coefficients of weights can be attributed to determine the eigenvectors and the largest characteristic value of judgment matrix. Step root law as follows:

a. Calculate the each row's elements' multiplication $\mathrm{M}$ of judgment matrix P.

$$
M_{i}=\prod_{j=1}^{N} u_{i j}, i=1,2, \cdots, N
$$

b. Calculate Nth root $\bar{W}_{i}$ of $M_{i}$

$$
\overline{W_{i}}=\sqrt[n]{M_{i}}, i=1,2, \cdots, N
$$


c.Normalize the vector $\bar{W}=\left[\overline{W_{1}}, \overline{W_{2}}, \cdots, \overline{W_{N}}\right]^{T}$

$$
W_{i}=\overline{W_{i}} / \sum_{j=1}^{n} \overline{W_{j}}
$$

$W=\left[W_{1}, W_{2}, \cdots, W_{N}\right]^{T}$ is the feature vector we ask for. It's elements are weight coefficient.

According to the above description, you can calculate the weight coefficient of employee human capital A, the employee level B, and Personal Accomplishment C. Assume that the conclusion is scored by experts: A slightly more important than B, A extremely important than the C, B slightly more important than $\mathrm{C}$, then according to the commonly used 1 to 9 scale method to build judgment matrix as follows:

$$
P=\left[\begin{array}{ccc}
1 & 3 & 9 \\
1 / 3 & 1 & 3 \\
1 / 9 & 1 / 3 & 1
\end{array}\right]
$$

Has been calculated, the feature vector is $W=\left[\begin{array}{lll}9 / 13 & 3 / 13 & 1 / 13\end{array}\right]^{T}$.

In summary, each node weight $=3 / 13 *$ Staff level $+9 / 13 *$ Human Capital $+1 / 13 *$ Personal accomplishment. Assume that $\sigma=1$, the node weights are in the following table. (Table4).

Table 4 Node weight

\begin{tabular}{|c|c|c|c|c|}
\hline Level of Position & $\begin{array}{c}\text { Employee's } \\
\text { level }\end{array}$ & $\begin{array}{c}\text { Human } \\
\text { Capital }\end{array}$ & $\begin{array}{c}\text { Personal } \\
\text { accomplishment }\end{array}$ & $\begin{array}{c}\text { Complex } \\
\text { weights }\end{array}$ \\
\hline Senior manager/Executive & 6 & $9.7 \sigma$ & 0.77 & 8.066 \\
\hline Junior manager/Executive & 5 & $5.3 \sigma$ & 0.5 & 4.847 \\
\hline $\begin{array}{c}\text { Experienced } \\
\text { supervisor(Branch) }\end{array}$ & 4 & $2.8 \sigma$ & 0.67 & 2.906 \\
\hline $\begin{array}{c}\text { Inexperienced } \\
\text { supervisor(Division) }\end{array}$ & 3 & $2.4 \sigma$ & 0.47 & 2.384 \\
\hline Experienced employee & 2 & $1.4 \sigma$ & 0.5 & 1.466 \\
\hline Inexperienced employee & 1 & $1.3 \sigma$ & 0.47 & 1.165 \\
\hline Administrative clerk & 1 & $1.25 \sigma$ & 0.5 & 1.133 \\
\hline
\end{tabular}

\subsection{Draw Network Diagrams Preliminarily.}

In order to draw network diagrams, we should allocate staff at all levels to each department according the figure title gives. So we make the following assumptions (following notation in parentheses is for A: Senior Manager /Executive; B: Junior manager/Executive; C: Experienced supervisor (Branch); D: Inexperienced supervisor (Division); E: Administrative clerk; F: employees. The number before alphanumeric is expressed as the staff's number):

CEO positions (4A); Research (1A, 1B, 2E); CIO (1A, 1B, 1C, 1D, 4E, 6F); CFO (1A, 1B, 1C, 1D, 4E, 6F); HR (1A, 1B, 2E);VP (1A, 1B, 2E); Facilities(2B, 2E); Sales Marketing(1A, 1B, 2E); Project Manager (6B, 3E, 5F); Product Manager (6B, 2E, 1C, 5F); Research's network (1C, 2D, 1E, 10F); Research's information department (2C, 1D, 10F, 1E); Plant Blue(1C, 2D, 1E, 10F); Plant Green(1C, 2D, 1E, 10F); Regional(2C, 1D, 10F, 1E); World Wide (2C, 1D, 10F, 1E); Internet (2C, 1D, 10F, 1E); 6 Production Manager's Director (2C, 2D); branch A to branch L (14F).

Use PAJEK to draw the initial network diagram: 


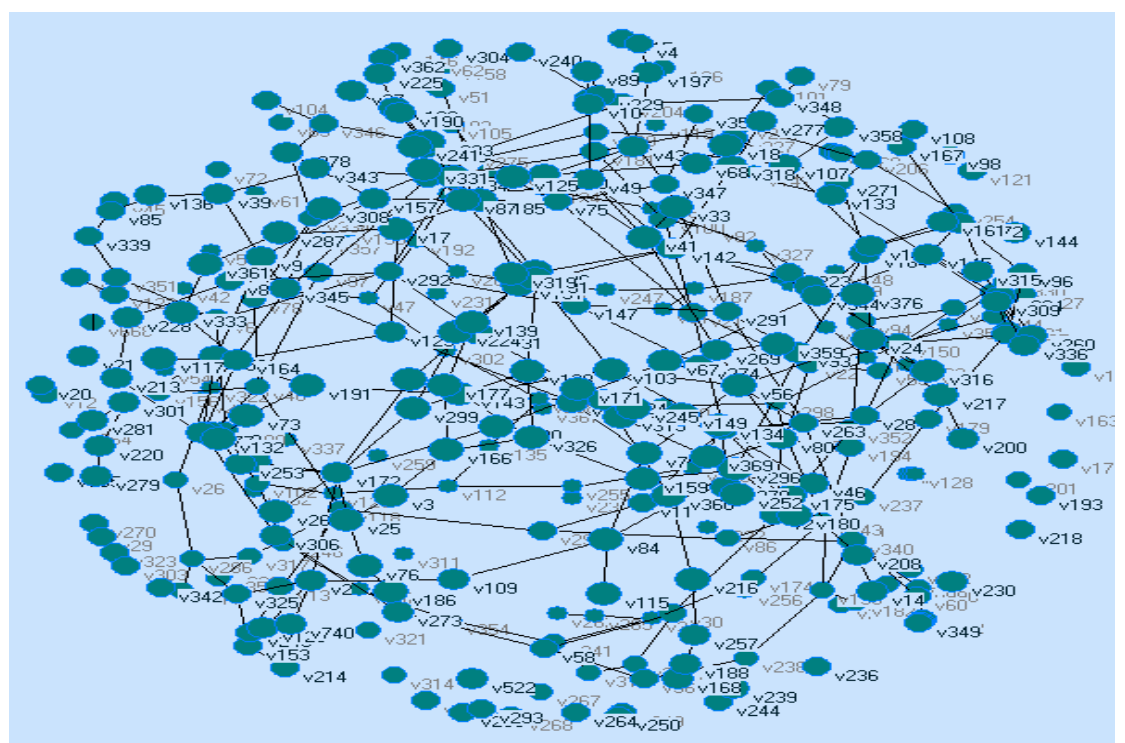

Fig. 2 Network diagram

\section{Build Multilayer Complex Network Model}

According to the initial network in 2.1, it is known that the network is complex. In order to facilitate research, the human capital in this article should be stratified network. Assume that the node weights 0-2 for low-level employees; node weight of 2 to 5 for middle-level cadres; node weight is 5 or more for senior cadres.

Let the network part to be decomposed (denoted as $\mathrm{W}$ ) have $\mathrm{m}$ start nodes and $\mathrm{n}$ end nodes. Denoted as $a_{1}, a_{2}, \ldots a_{n}$ and $b_{1}, b_{2}, \ldots b_{n}$. Denote the decomposed sub-network as $\mathrm{S}$. The layering principles are: (1) All start nodes and end nodes in W are reserved in S, and these start nodes and end nodes are migrated to $S$ as they are. Still use these as the start and end nodes of $S$ (can be renumbered). (2) If the node $\mathrm{k}$ appearing in $\mathrm{W}$ is the intersection point of the route in $\mathrm{W}$ (not the duplicate point), it remains in $\mathrm{S}$ (can be renumbered). (3) The node $\mathrm{k}$ that does not appear in $\mathrm{W}$ but belongs to decision points will be reserved in $\mathrm{S}$ (can be renumbered). (4) If there is a route $L\left(a_{i}, k\right)$ between $a_{i}$ and $\mathrm{k}$, it is decomposed into a network part component in the next layer of subnet $\mathrm{S}$, where $a_{i}$ is the start node and $\mathrm{k}$ is the end node. The length of its critical path is equal to the length of $L\left(a_{i}, k\right)$. (5) If there is a route $L\left(k, b_{j}\right)$ between $\mathrm{k}$ and $b_{j}$, it is decomposed into a network part component in the next layer of subnet $\mathrm{S}$, with $\mathrm{k}$ as the start node and $\mathrm{b}$ as the end node. The length of its critical path is equal to the length of $L\left(k, b_{j}\right)$. (6) If there exists a route $L\left(a_{i}, b_{j}\right)$ between $a_{i}$ and $b_{j}$ in $\mathrm{W}$, it is decomposed into a route in the next sub-network $S$. Based on this, it is expanded into components. Take a as the beginning node and $b_{j}$ as the end node. The length of its critical path is equal to the length of $L\left(a_{i}, b_{j}\right)$ [2].

To describe easily, the total network, each sub-network of the node numbers are different. The total net position $\mathrm{G}()$ is represented by the value of the underlying network plan and the second sub-networks SI are stand for each department. In the tables: B stand for a sector; N stand for number of nodes; W stand for node's weight.

1. First network - senior cadres Network 
Table 5 First layer of the network, high-level cadres network G.

\begin{tabular}{|c|c|c|}
\hline $\mathbf{B}$ & $\mathbf{N}$ & $\mathbf{W}$ \\
\hline CEO & $1,2,3,4$ & 8.066 \\
\hline Research's Senior manager/Executive & 5 & 8.066 \\
\hline CIO's Senior manager/Executive & 9 & 8.066 \\
\hline CFO's Senior manager/Executive & 23 & 8.066 \\
\hline HR Senior manager/Executive & 37 & 8.066 \\
\hline VP Senior manager/Executive & 41 & 8.066 \\
\hline Sales Marketing Senior manager/Executive & 49 & 8.066 \\
\hline
\end{tabular}

2. Second layer of the network - mid-level network

Table 6 Second layer of the network - mid-level network

\begin{tabular}{|c|c|c|}
\hline B & N & W \\
\hline CIO's Junior manager/Executive & 10 & 4.847 \\
\hline CIO's Director & 11 & 2.623 \\
\hline
\end{tabular}

There are 7 sub-networks in the second layer of the network in total. Not repeat.

3. Third layer of the network - the underlying employee network

Table 7 Third layer of the network - the underlying employee network.

\begin{tabular}{|c|c|c|}
\hline $\mathbf{B}$ & $\mathbf{N}$ & $\mathbf{W}$ \\
\hline CFO's Administrative clerk & $27,28,29,30$ & 1.133 \\
\hline CFO's employee & $31,32,33,34,35,36$ & 1.255 \\
\hline
\end{tabular}

There are 7 sub-networks in the third layer of the network in total. Not repeat.

\section{Characteristics of Network Topology}

\subsection{Clustering Coefficient.}

According to graph theory, clustering coefficient is a coefficient which represents the degree of aggregation nodes in a graph. Supposing node $i$ is connected with other $k_{i}$ nodes in the network. There might be $k_{i}\left(k_{i}-1\right) / 2$ edges between the $k_{i}$ nodes at most. The actual existence of the total number of edges $E_{i}$ between these $k_{i}$ nodes and the number of possible edges $k_{i}\left(k_{i}-1\right) / 2$ are defined as the clustering coefficient $C_{i}$ of node $i$, and could be expressed as $C_{i}=\frac{2 E_{i}}{k_{i}\left(k_{i}-1\right) / 2}$ [4]. The clustering coefficient of the whole network is the mean value of $C_{i}$, expressed as $C=\frac{1}{n} \sum_{i} C_{i}$. Combined with the actual network data and the PAJEK software, we know that the average of the clustering coefficient of human capital network $C=0.0107659$. As can be seen from the calculation results, $C=0.0107659$ satisfies the condition of the clustering coefficient values less than 1 but greater than 0 . Therefore, we can determine the network has clustering effect.

\subsection{Density of Network.}

Network's density refers to communication between the nodes tightness of a network. More connections between network nodes, the bigger density of network. For undirected networks, network density can actually use the network connections actually exist divide connections may exist. Combined with the actual data from the network, using PAJEK software to calculate, we get human capital network nodes $\mathrm{N}=370$, the number of connections $1=389$, network density for $\mathrm{d}=0.25099$. According to the calculated values can understand the connection between human capital in the whole range of node network more closely, there is widespread, a close exchange relation. 


\section{Summary}

Because the network consists of basic human capital as well as the flow of personnel, training, the work of school performance, and other elements, the churn of persons is determined by loyalty of employee, human capital and satisfaction. Therefore, the paper build the network model will not only consider the organization of employees and human capital, and build a network that be consist of interrelated layers. The basic idea of the complex network model can be well applied to the construction of the personnel evaluation index system. On this basis, the follow-up work will pay more attention to empirical research in this area.

\section{References}

[1]. Xue Deng, Jiaming Li, Haojian Zeng, et al. Analytic Hierarchy Weights Calculation Methods and Application Research, Mathematics in Practice and Theory, Vol. 42 (2012) No. 7, p. 93-99.

[2]. Lin Li, Layering Technology and Application Network (PhD, China, Hunan University, 2001). p. 26

[3]. Wei Shao, Monte Carlo Method and its application in some statistical models (PhD, China, Shandong University, 2012). p. 67

[4]. Lanhua Zhang, Research on Simulation and Application of Complex Network Modeling, (PhD, China, Dalian University of Technology, 2001). p. 43

[5]. Xiaohua Sun, Zhendong Qi, Xingming Duan, The cost of the loss of corporate officers - Benefit Dynamic Control Model Analysis, Vol. 23 (2006) No. 9, p. 155-157.

[6]. Yanhua Shu, Research on Human Resource Management Evaluation Model Based on Bayesian Network(Master, China, Hefei University of Technology,2006)

[7]. Weixi Zeng, Constructing Personnel Evaluation Index System Based on Complex Network Model, Vol. 33(2013) No.1, p. 84-86 